\title{
Non-stop equity: \\ Assessing daily intersections between transit accessibility and social disparity across the Greater Toronto and Hamilton Area (GTHA)
}

\author{
El-Geneidy, A., Buliung, R., Diab, E., van Lierop, Langlois, M., \& Legrain, A.
}

April 2015

Paper accepted for publication in Environment and Planning B: Planning and Design.

Public transportation systems generate economic benefits that can potentially reduce social disparities between populations when such benefits are distributed evenly within a region. However, the achievement of equity in the allocation of public resources is not easy to accomplish for land use and transportation planning agencies. This research seeks to determine whether people residing in socially disadvantaged areas in the Greater Toronto and Hamilton Area (GTHA), Canada, experience the same levels of transit accessibility as those living in other areas over the course of a day. Comparisons are presented in terms of regional accessibility, trends by social decile, spatial distribution of accessibility during the day, and travel time impacts. Findings suggest that residents in socially disadvantaged areas have equitable if not better transit accessibility to jobs than socially advantaged groups, and this is reflected in shorter travel times. However, the degree and impact of this advantage varies over the course of the day. Findings from this research can be of interest to transportation planners, engineers and policy makers as it highlights deficiencies with current equity assessment practices that do not take into account variation in transit services over a 24 -hour time period.

Keywords: Equity, Transit accessibility, Competitive accessibility, Travel time, Low-wage jobs

\section{ACKNOWLEDGEMENT}

The authors would like to thank Metrolinx for funding this research. Also we would like to thank Guillaume Barreau for modeling the transit trips to between home and work locations in Google Maps. Thank you also to Andrew Byrd from Conveyal for his help with the accessibility measures and to the three anonymous reviewers for their helpful insight.

For citation please use: El-Geneidy, A., Buliung, R., Diab, E., van Lierop, Langlois, M., \& Legrain, A. (2016). Non-stop equity: Assessing transit accessibility and social disparity over time. Environment and Planning B: Planning and Design, 43(3), 540-560. 


\section{INTRODUCTION}

Achieving equity in the allocation of public resources is a long-term goal for many pubic urban planning and transportation agencies. Public transportation systems generate economic benefits that can work to reduce economic disparities when transit supply is distributed fairly among different population groups within a region (Grengs, 2010; Jones \& Lucas, 2012). Public transportation benefits can include: high access to desired destinations, shorter travel times, extended operating hours, and shorter waiting and transfer times (Foth, Manaugh, \& El-Geneidy, 2013). In other words, the location, quality and level of service provided affect people's economic and social opportunities. A fair distribution of transportation resources is expected to provide a variety of options for commuters who do not have many travel choices, and also provide them with shorter commuting times (Krumholz \& Forester, 1990). In contrast, an inequitable distribution may harm socially and economically disadvantaged groups (Sanchez, Stolz, \& Ma, 2003). Public transit is expected to provide accessibility to desirable and/or necessary destinations. It is important to understand the spatial and temporal availability of transit services to socially disadvantaged residents because they are more likely to be transit-captive. Furthermore, to mitigate socio-economic disparities within a city and reduce some of the burdens imposed upon and experienced by disadvantaged populations it is crucial to consider their ability to reach desired or necessary destinations using transit.

This study explores whether people residing in socially disadvantaged areas in the Greater Toronto Hamilton Area (GTHA) experience the same levels of accessibility to jobs using public transit compared to those living in other areas over the course of a day. It also seeks to find out whether these levels of accessibility are reflected in shorter travel times for socially disadvantaged groups. These objectives are relevant as they reflect the equity goals of The Big Move, the regional transportation planning authority's (Metrolinx) regional transportation plan (Metrolinx, 2008). The accessibility measures developed in this paper go one step further than most previous accessibility studies; usually, one measure is used to represent daily levels of transit service. In contrast, this paper presents six separate measures that indicate accessibility at different times of day. Times and areas where service is lacking and demand is forthcoming are discovered using these measures. In this way, this measurement approach is dynamic: it takes into account daily fluctuations in service and job availability, and the ease different locations have reaching employment. Using this measure the region's most vulnerable populations' levels of transit service are spatially and temporarily assessed. Although the context of this study is the GTHA, Canada's largest urbanized region, other regional transit agencies have plans with similar equity goals can benefit from this study. Also the methodology developed in this research as well as its findings can be of benefit to these other agencies. 


\section{LITERATURE REVIEW}

\section{Equity and Transportation Planning}

Equity issues are a concern in multiple disciplines, including economics (Atkinson, 1983; Duclos \& Araar, 2007), law (Louka, 2006), and medicine (Williams \& Cookson, 2000). However, the way in which the concept of equity is understood varies. In economics, equity is about "how the economic 'pie' is divided up" (Field \& Olewiler, 2011, p. 4), whereas the Oxford English Dictionary defines equity as the "quality of being fair and impartial" (Soanes \& Stevenson, 2003). Therefore, it can be assumed that equity relates to the distribution effects on individuals and is assessed according to the fairness of this distribution. However, what can be considered an equitable distribution is complex and differs among individuals since moral judgments and sociocultural norms are often involved (van Wee \& Geurs, 2011).

There are three common types of equity on which transportation analyses are based: horizontal equity, vertical equity, and intergenerational equity. Horizontal equity refers to the equal distribution of effects (benefits and costs) among individuals. This type of equity, which comes from egalitarian theories, avoids favoring one individual or group over another one (Litman, 2002). In contrast, vertical equity requires special considerations for socially and economically disadvantaged groups in the sense that benefits should be intentionally provided to them (Murray \& Davis, 2001). In this case, rather than providing the benefits for each individual or group, vertical equity stipulates that the division of benefits should be directed, in greater proportion, to those with the greatest potential need (Litman, 2002). Within the field of transportation planning, Martens et al. (2012) - who were inspired by the concept of vertical equity - suggest that the evaluation of transportation equity should be based on Rawls' Theory of Justice (1971). There are two central points to their method: the average access to transportation and opportunities should be maximized while (a) maintaining a certain minimum for all and (b) containing the range of access (maximum gap) in order to prevent excessive disparities.

In terms of operationally measuring equity concepts, researchers use different statistical dispersion tools such as the Gini coefficient (Delbosc \& Currie, 2011; Geurs \& van Eck, 2001; Kaplan, Popoks, Prato, \& Ceder, 2014), the Theil index (Delafontaine, Neutens, Schwanen, \& Van de Weghe, 2011; Santos, Antunes, \& Miller, 2008), the range (Foth et al., 2013), and the coefficient of variation (Ramjerdi, 2006; Talen, 1998) to conceptualize and estimate inequalities. See Ramjerdi (2006) for an extensive analysis of equity measures. From the most complex to the simplest measures, inequality is understood through the range or gaps in the distribution of the goods in question. Therefore, this analysis uses the range as a measure of equity (van Wee \& Geurs, 2011). The range is the most common and understood measure of dispersion. It is defined as the difference between the lowest and the highest value. For this paper this difference is the range in transit accessibility that residents of disadvantaged areas experience compared to residents of better-off areas. It should also be noted that intergenerational equity considers the fair distribution of goods across generations (Litman, 2002; van Wee \& Geurs, 2011). This type of equity is not examined here; rather, this paper focuses on vertical equity in transit service over a 24-hour time period, rather than comparing changes in accessibility over years or decades (for an intergenerational study see, Foth et al., 2013).

Transportation equity is related to the spatial, temporal and socio-demographic inequalities or gaps in the distribution of transportation supply and the benefits this supply offers to certain populations (Jones \& Lucas, 2012). One assessment example is a study by Delbosc and Currie (2011), which assessed horizontal and vertical equity in Melbourne, Australia. They found 
that low-income households in the inner city experienced relatively high access to transit, while spatial inequality is observed in the outer regions. Scott and Horner (2008) investigated whether or not seven different counties in Louisville, USA were developed in such a way that locations of opportunities vary between groups at risk of social exclusion and wealthier groups. A Canadian study by Foth et al. (2013) analyzed changes to transit service between 1996 and 2006 to see if equity increased or decreased in the city of Toronto. These studies suggest that a fair distribution of transportation supply among socio-economic groups occurs in their study areas. Scott and Horner (2008) found that groups considered to be at risk of social exclusion are not disadvantaged in term of accessibility to goods and services, whereas Foth et al. (2013) found that socially deprived zones experienced better transit accessibility and lower travel times compared to better-off zones.

\section{Accessibility Measurement and the Equity Concept}

One way to study equity issues in transportation is to evaluate the effectiveness of the service provided by transit agencies among different stratified socio-economic groups using accessibility and mobility measures as indicators of transit supply. Accessibility measures quantify how many "potential opportunities for interaction" can be reached using a certain travel mode (El-Geneidy \& Levinson, 2006; Handy \& Niemeier, 1997; Hansen, 1959), while mobility is a measure of the ability to move between different places (Morris, Dumble, \& Wigan, 1979). There are four types of accessibility measures: infrastructure-based, locations-based, person-based, and utility-based (for an extensive review of these measures see (Geurs \& van Eck, 2001) and (Geurs \& Van Wee, 2004)). Most transport equity studies are limited in their assessment of opportunities that people actually want to or need to reach and ignore competition among individuals in using these opportunities. Much of the literature also disregards the fact that not all opportunities will be equally interesting or easily accessed, i.e., in a socio-cultural or economic sense, to all populations. For instance, in the case of job opportunities, job-matching considerations needs to be taken into account as well as competition among workers (Shen, 1998). If many individuals are competing for the same opportunities within an area, the chance to gain that opportunity is lower than in a situation where there are plenty of desired opportunities and fewer competitors (Shen, 1998). The competition for opportunities in a region is also expected to impact travel time by different modes (Kawabata \& Shen, 2006; Levinson, 1998).

In transportation research, it is common practice to calculate accessibility for an area at a specific time and use this measure to approximate the daily accessibility experienced. However, some studies have indicated that ignoring daily variation in transit schedules can overestimate the accessibility actually experienced by commuters (Anderson, Owen, \& Levinson, 2012; Kim \& Kwan, 2003). In fact, the assumption that accessibility stays constant throughout the day cannot accurately be made regarding transit systems since transit frequency and, therefore, travel-time fluctuate over the day. Owen and Levinson (2013) show that these fluctuations can be quite substantial even within an hour. What has not been coupled with these more dynamic measures of accessibility are data on when jobs are available (job start times). Given variability in service level, it is possible that certain socially and economically disadvantaged groups only have acceptable access to desired possibilities (such as jobs) via transit during specific periods. At other time periods, there may be a spatial and temporal mismatch, as the geography of the network changes through time.

The idea of temporal mismatch is indebted to the well-researched spatial mismatch phenomenon. Spatial mismatch occurs when poor workers, usually of a disadvantaged ethnic 
group residing in inner-city areas, cannot access suburban employment opportunities (Kain, 1968, 1992). Spatial mismatches have also been observed in other countries where emphasis is placed on spatial rather than ethnic/racial inequalities (Houston, 2005). Modal mismatch is a related concept that refers to the difficulty or lack of accessibility encountered by car-less individuals trying to reach various destinations (Grengs, 2010). Mismatch research suggests that areas can be inaccessible due to insufficient transit provision, and this inaccessibility can vary in strength during a 24-hour time period. Therefore, not assessing transit accessibility to jobs by transit over the course of the day may improperly estimate transit benefits for socially disadvantaged groups.

Assessing for changing schedules by analyzing accessibility over the course of one day is essential for transportation equity studies attempting to determine whether benefits of public transit are fairly distributed among population groups. In addition, assessing this level of access through a combination of transit schedule data and job start times takes accessibility research into a new area of exploration. Presently, however, few accessibility studies (Anderson et al., 2012) have tried to control for changing transit service levels over time, and, to our knowledge, the fairness of the distribution of a transit system's benefits have never been evaluated by time of day for socially disadvantaged and non-socially disadvantaged groups. In addition the impact of the temporal distribution of a transit system's benefits on different groups' experienced travel time has not, to our knowledge, been explored in the literature. Finally, accounting for the temporal availability of opportunities, and the way competition for these opportunities changes over the day, is another dimension that, to our knowledge, has not been explored in an equity study.

\section{STUDY CONTEXT}

This study focuses on the entire GTHA, which is an urban area in Ontario, Canada, composed of multiple cities and regions: the City of Toronto, the City of Hamilton, and the Halton, Peel, Yorkand Durham regions (see Figure 1). For the purposes of this study, the City of Toronto is divided into two distinct areas referred to as Toronto inner-suburbs and Toronto (preamalgamation), which is the City of Toronto boundary before it was amalgamated in 1993 with its inner suburban boroughs. A commuter rail system (the GO Train), a centrally located subway system and streetcar network, and bus services that are provided by multiple transit agencies (eight in total) collectively serve the GTHA.

The GTHA is a dynamic area where the population is growing constantly, particularly within the outer suburbs. Employment suburbanization is observed in the region as well (Shearmur, Coffey, Dube, \& Barbonne, 2007). In 2011, the population of the area was 6,574,140. At that time the region had 2,678,170 workers and 2,759,180 jobs (Shearmur et al., 2007). There are more jobs in the region than workers to fill them, meaning that the attractive power of the region is strong enough to draw workers from beyond its boundaries.

This study uses census tract (CT) level data. Census tracts are small geographic areas used by Statistics Canada to conduct various surveys, including its quinquennial Census and National Household Survey. Census boundaries are determined by population, which is usually between $2,500-8,000$ persons per census tract. In the area of study, there are 1,328 CTs, with an average area of $5.53 \mathrm{~km}^{2}$, and an average population of 4,925 persons. 


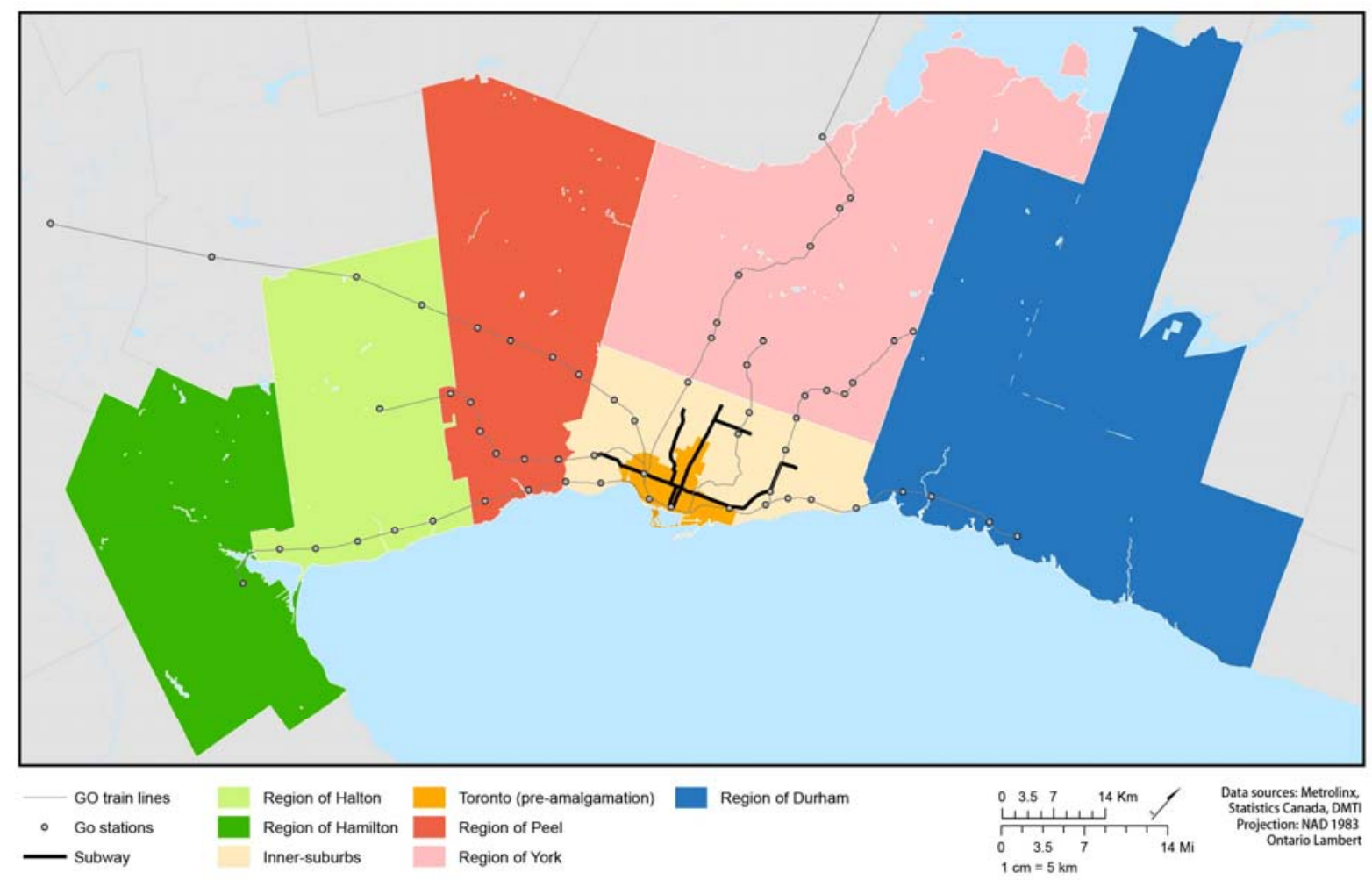

\section{Figure 1: Greater Toronto and Hamilton Area}

\section{DATA AND METHODOLOGY}

To analyze the equity of job accessibility among socially disadvantaged groups compared to the rest of the population in the GTHA accessibility changes over time are determined using both spatial and temporal measurements. Three main data sources are used including the 2011 National Household Survey (NHS) provided by Statistics Canada. The data are organized in a matrix of CT origins and departures, with corresponding total numbers of travelers as well as travelers by mode for each trip during six time periods. The six time periods analyzed are based on travelers' departure time: from 5am-6am, 6am-7am, 7am-8am, 8am-9am, 9am-Noon, and Noon-5am. The 9am-Noon and Noon-5am collapses occur because data is suppressed in the National Household Survey when cells contain less than five observations, a frequent occurrence during these time categories. Therefore, to avoid errors in calculations due to empty cells, this temporal classification was provided by Statistics Canada. The data was further divided according to job category, which will be discussed in detail in below.

The second data source is demographic census tract (CT) information provided by Statistics Canada from the 2011 NHS. These data include information related but not limited to residents' median incomes, unemployment rates, and percentage of immigrants. They are used to determine regional social and economic deprivation. The final data source is a transit travel time matrix based on May-June 2014 General Transit Feed Specification (GTFS) data for the eight transit agencies of the GTHA. This dataset is used to determine travel times between CT origin and destination centroids using Geographic Information Systems software. 


\section{Social Deprivation Indicator}

With the assumption that socially disadvantaged groups are spatially concentrated (Ades, Apparicio, \& Séguin, 2012; Townsend, Phillimore, \& Beattie, 1988), a composite indicator of social deprivation, at the CT level, is calculated using 2011 NHS data to identify the most deprived zones in the GTHA. This indicator, which was developed in previous research (Foth et al., 2013), is composed of four equally weighted variables: median income, unemployment rate, zone share of residents who immigrated to Canada in the past five years, and zone share of tenants spending more than $30 \%$ of their income on rent. Each variable was normalized using a $\mathrm{z}-$ score, then a total z-score was generated by summing all previously mentioned normalized variables (see Foth et al. (2013) for details of this measure). The indicator is grouped by deciles and helps to identify the $10 \%$ most deprived zones. In the analysis, the first decile represents the most socially disadvantaged CTs, while the tenth decile accounts for the least socially disadvantaged CTs. The statistical analyses presented in this paper compare the first decile (most socially disadvantaged CTs) to the average of all other deciles taken together (all other CTs).

\section{Accessibility Measure}

To better understand how the GTHA's transport agencies are serving the region spatially over the course of the day while accounting for equity issues, two working population groups are assessed: the total working population who earns $\$ 16.00$ an hour or less, and those who earn more than $\$ 16.00$ an hour. These income cut offs are used because $\$ 16.00$ is considered to be the living-wage for Toronto (Mackenzie \& Stanford, 2008). Throughout the analysis, jobs that pay $\$ 16.00$ an hour or less are referred to as 'low-wage jobs', and those that pay more as 'other-wage jobs.' The list of National Occupation Classification (NOC) subcategories that make on average less than or equal to $\$ 16.00$ an hour in the Toronto Census Metropolitan Area is generated using the most recent Canada Job Bank 'wages for Toronto' (Government of Canada, 2014). The accessibility measures are based on actual transit travel times at each of the time periods in question, allowing for the incorporation of job availability at each time period with the transit service available at that period. For each group of jobs, two measures of transit accessibility are calculated at the census tract level: a gravity-based measure and a competitive accessibility measure. ${ }^{1}$ Throughout the paper, standardized values (z-scores) of accessibility are used to compare results. This is necessary because each measure is calculated for not just one time period, but for six time periods. Comparison across the day required standardization of these measures so that the magnitude in difference would not distract from the relative change that occurs.

\section{Transit Travel Time \& Mean Travel Time per CT}

In addition to the broad measure of regional accessibility, transit travel time from home locations to work locations at the CT level for the working-aged population (15-64 years old) is also estimated. Transit travel time from every CT centroid to every other CT centroid is used to calculate the accessibility measures' impedance $(\beta)$ functions. The travel time from each CT centroid to every other CT centroid at each departure time period is calculated using current GTFS data for all eight public transit agencies serving the GTHA. These calculations provide a

\footnotetext{
${ }^{1}$ Please see the supplementary files for a detailed explanation of the measures used.
} 
departure travel time matrix for each period showing travel times from each CT to every other CT. These transit times are estimated using the OpenTripPlanner Analyst, provided by Conveyal ("OpenTripPlanner," 2014), which uses GTFS data to determine which route is the fastest option between two points at a certain departure time, and records the time it would take.

Travel times from each CT to all other CTs are measured for departures at the top of the hour for each hour under question. Walking time is used if walking is the fastest option for a trip pair at a particular hour. Furthermore, walking times to and from stations to CT centroids are included in the total travel time. For one of the collapsed time periods (9:00 am to noon and noon to 5:00 am) a mean travel time is calculated. However, for the noon to 5:00 am period, travel time at noon is used because of misleadingly long transit times measured during the early morning hours (when most transit systems are closed). Commute time estimates include access and egress time, wait time, in vehicle time, and transfer time. Average CT travel time is the commuter frequency weighted mean travel time for each CT. This was calculated for every departure period. However, several CTs did not have any departures during certain time periods; these zones were excluded from the analysis during missing data time periods. The average number of CTs included in the analysis for each time period is 500 (out of approximately 1300), with a standard deviation of 438 .

\section{REGIONAL ACCESSIBILITY TRENDS}

\section{Spatial Distribution of Jobs and Transit-Dependent Workers at the CT Level}

While there is a certain concentration of socially disadvantaged CTs in Toronto (preamalgamation) (18\%), most of the socially disadvantaged CTs are located in the inner-suburbs of Toronto (56\%). They are also found further from the downtown Toronto in the outer suburban regional municipalities of Peel (16\%), Durham (1\%) and York (1\%) and in the City of Hamilton $(8 \%)$. The distribution of socially deprived zones may be related to a suburbanization of socially disadvantaged populations, which is a growing trend and challenge within Canadian metropolitan regions (Ades et al., 2012). This new dispersion of socially disadvantaged groups throughout metropolitan areas may be due to a variety of inter-connected reasons, including increases in housing prices in the Toronto centre (Bunting, Walks, \& Filion, 2004), the suburbanization of jobs (Shearmur \& Coffey, 2002), as well as improvements to the transit network (Foth et al., 2013).

Figures 2 and 3 display the spatial distribution of gravity and competitive standardized accessibility to low-wage jobs and to all other jobs by CT during two time periods: from 5:00 am to 6:00 am and from 7:00 am to 8:00 am, respectively. These two time periods are provided as an example of changes in accessibility over time. Great disparities in accessibility to jobs by public transit between CTs are observed depending on the accessibility measure used. Generally, the gravity accessibility maps show that higher levels of accessibility spread outward in the region, with the core having access to the greatest number of jobs. Near the airport, which is located to the northwest of the City of Toronto, CTs host more low-wage jobs during the 5:00 am to 6:00 am period. The competitive accessibility measure produces different results. Accessibility to lowwage jobs and all-other jobs is centered on the west side of the study area in the Halton and Peel regions. Toronto (pre-amalgamation) shows better competitive accessibility during the 5:00 am to 6:00 am period compared to the 7:00 am to 8:00 am period. 


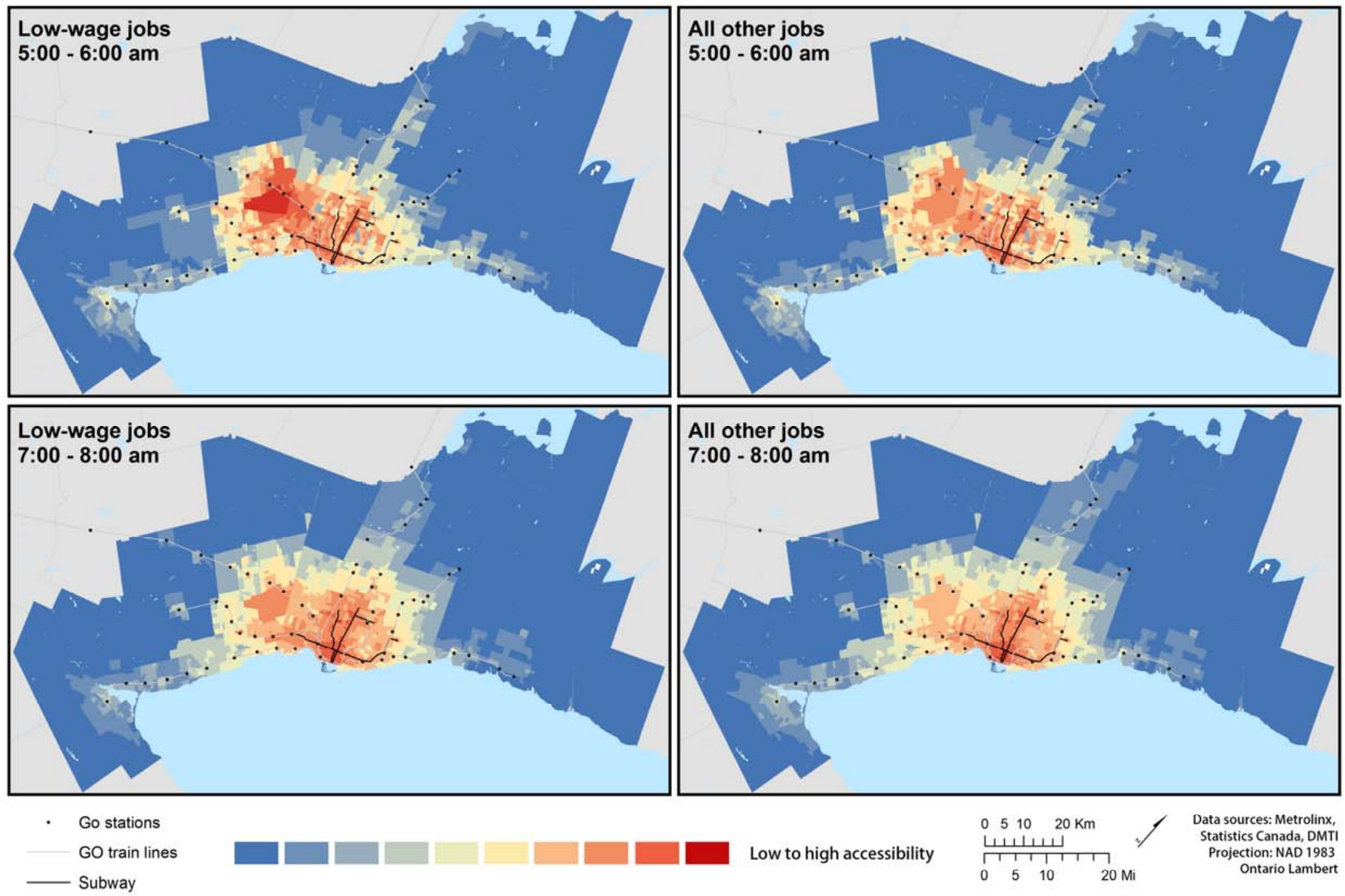

Figure 2: Relative accessibility to low-wage jobs and all other jobs measured with the gravity measure, 2011 


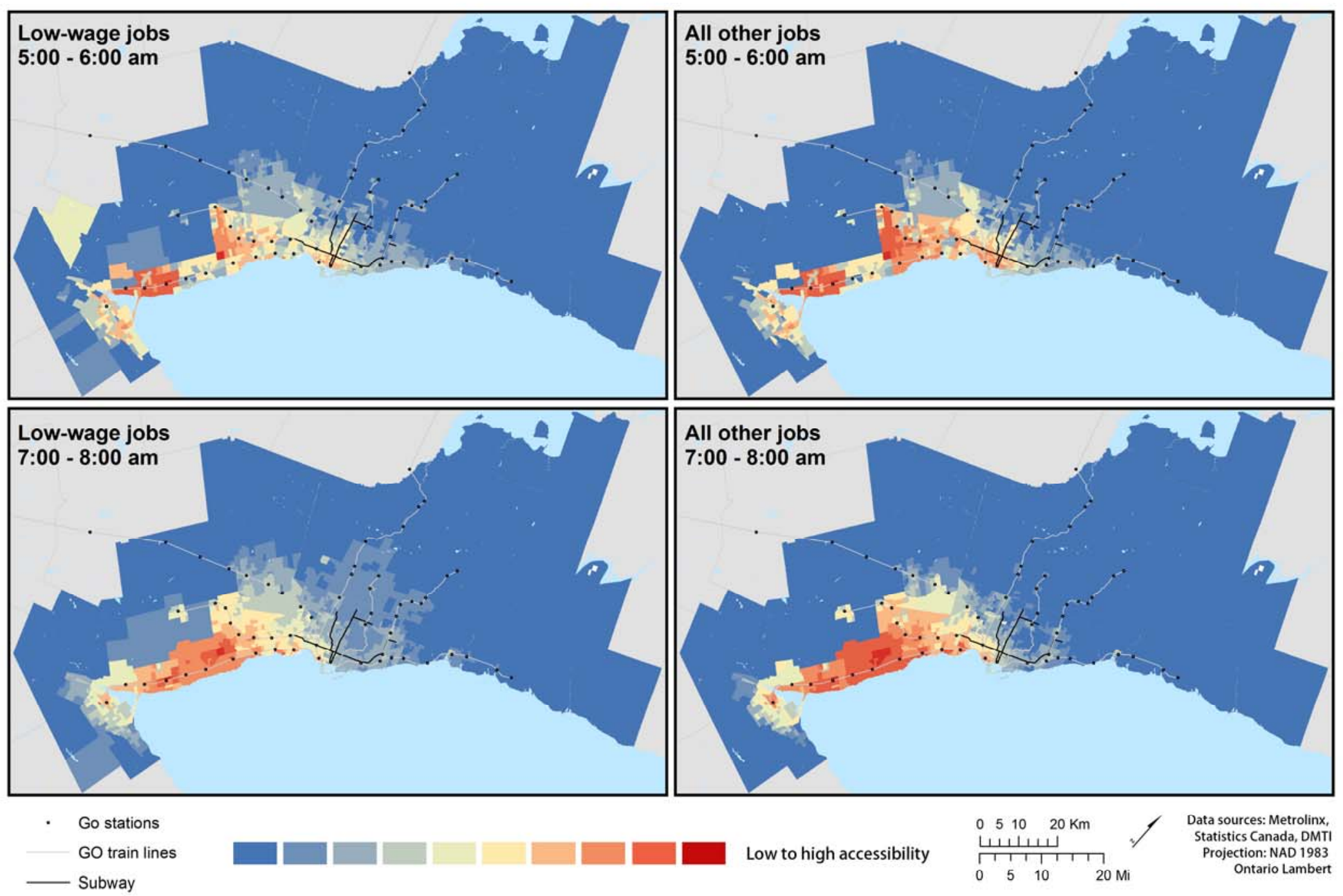

Figure 3: Relative accessibility to low-wage jobs and all other jobs measured with the competitive measure, 2011 
Table 1 presents the standardized descriptive statistics of accessibility. The table compares accessibility to low-wage jobs and all other jobs for the most socially disadvantaged zones and for all other zones. This table also provides travel time statistics. The table makes clear that both gravity and competitive accessibility to both low-wage jobs and all other jobs for the most socially disadvantaged zones is always greater than accessibility from other zones. These findings indicate that the most socially disadvantaged zones generally have better objectively measured accessibility, combined with shorter travel times, than all other CTs. As can be seen, only a few statistically significant differences in accessibility are found. Due to this finding, the following sections further discuss the results by focusing on both time period and spatial location of the CTs. For simplification, the discussion will only use the competitive accessibility measure, as it accounts for demand-side competition (e.g. workers) and is the more theoretically and empirically robust method (Shen, 1998). 
Table 1: Standardized descriptive statistics

\begin{tabular}{|c|c|c|c|c|c|c|c|c|c|c|c|}
\hline \multirow[b]{2}{*}{$\begin{array}{l}\text { Accessibility } \\
\text { measure }\end{array}$} & \multirow[b]{2}{*}{ Time } & \multicolumn{5}{|c|}{ Low-wage jobs } & \multicolumn{5}{|c|}{ All other jobs } \\
\hline & & Range & Min. & Max. & Mean & $\begin{array}{l}\text { Std. } \\
\text { Dev. }\end{array}$ & Range & Min. & Max. & Mean & $\begin{array}{l}\text { Std. } \\
\text { Dev. }\end{array}$ \\
\hline \multirow{6}{*}{ 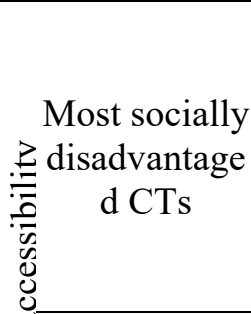 } & $5-6$ AM & 3.64 & -1.61 & 2.03 & 0.69 & 0.65 & 3.87 & -1.65 & 2.23 & 0.74 & 0.63 \\
\hline & $6-7$ AM & 3.70 & -1.50 & 2.20 & 0.70 & 0.69 & 3.98 & -1.47 & 2.52 & 0.70 & 0.73 \\
\hline & $7-8 \mathrm{AM}$ & 3.65 & -1.42 & 2.23 & 0.68 & 0.72 & 3.87 & -1.39 & 2.47 & 0.68 & 0.76 \\
\hline & $8-9$ AM & 3.56 & -1.39 & 2.18 & 0.69 & 0.73 & 3.81 & -1.33 & 2.48 & 0.69 & 0.78 \\
\hline & $9-12 \mathrm{PM}$ & 3.82 & -1.54 & 2.28 & 0.71 & 0.71 & 3.83 & -1.50 & 2.33 & 0.71 & 0.73 \\
\hline & $12-5 \mathrm{AM}$ & 5.19 & -1.52 & 3.67 & 0.53 & 0.73 & 3.79 & -1.58 & 2.20 & 0.71 & 0.68 \\
\hline & $5-6 \mathrm{AM}$ & 4.16 & -2.04 & 2.11 & -0.06 & 1.00 & 4.24 & -2.11 & 2.13 & -0.07 & 1.00 \\
\hline$\sqrt{2}$ & $6-7$ AM & 4.19 & -2.04 & 2.16 & -0.06 & 0.99 & 4.40 & -1.99 & 2.41 & -0.06 & 0.99 \\
\hline All other & $7-8 \mathrm{AM}$ & 4.08 & -1.88 & 2.20 & -0.06 & 0.99 & 4.21 & -1.83 & 2.38 & -0.06 & 0.99 \\
\hline CT & $8-9$ AM & 4.13 & -1.92 & 2.21 & -0.06 & 0.99 & 4.21 & -1.81 & 2.40 & -0.06 & 0.99 \\
\hline & $9-12$ PM & 4.20 & -1.92 & 2.28 & -0.06 & 0.99 & 4.15 & -1.85 & 2.31 & -0.06 & 0.99 \\
\hline & $12-5 \mathrm{AM}$ & 13.62 & -2.12 & 11.50 & -0.05 & 1.00 & 4.14 & -1.99 & 2.16 & -0.06 & 0.99 \\
\hline \multirow{6}{*}{ 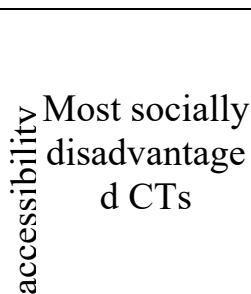 } & $5-6$ AM & 2.50 & -0.91 & 1.59 & 0.12 & 0.51 & 4.31 & -1.29 & 3.02 & 0.27 & 0.80 \\
\hline & $6-7$ AM & 3.23 & -0.98 & 2.24 & 0.07 & 0.63 & 3.99 & -1.21 & 2.78 & 0.14 & 0.77 \\
\hline & $7-8$ AM & 2.72 & -0.71 & 2.01 & 0.01 & 0.49 & 4.28 & -1.15 & 3.12 & 0.11 & 0.78 \\
\hline & $8-9$ AM & 2.02 & -0.58 & 1.44 & 0.02 & 0.37 & 4.02 & -1.02 & 3.00 & 0.11 & 0.70 \\
\hline & $9-12 \mathrm{PM}$ & 3.67 & -0.92 & 2.74 & 0.04 & 0.66 & 3.88 & -1.11 & 2.77 & 0.12 & 0.71 \\
\hline & $12-5 \mathrm{AM}$ & 3.38 & -1.00 & 2.38 & 0.07 & 0.68 & 3.35 & -1.19 & 2.16 & 0.19 & 0.73 \\
\hline \multirow{6}{*}{ 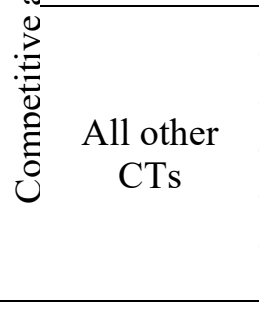 } & $5-6 \mathrm{AM}$ & 4.12 & -1.01 & 3.12 & -0.06 & 0.72 & 4.75 & -1.41 & 3.34 & -0.05 & 0.97 \\
\hline & $6-7$ AM & 5.29 & -1.11 & 4.17 & -0.04 & 0.85 & 5.48 & -1.38 & 4.10 & -0.03 & 0.99 \\
\hline & $7-8$ AM & 3.60 & -0.76 & 2.83 & -0.04 & 0.63 & 5.57 & -1.25 & 4.32 & -0.02 & 1.00 \\
\hline & $8-9$ AM & 2.98 & -0.65 & 2.34 & -0.05 & 0.54 & 5.71 & -1.16 & 4.55 & -0.02 & 1.01 \\
\hline & $9-12 \mathrm{PM}$ & 5.13 & -0.99 & 4.14 & -0.03 & 0.91 & 5.42 & -1.19 & 4.23 & -0.02 & 1.00 \\
\hline & $12-5 \mathrm{AM}$ & 5.49 & -1.06 & 4.43 & -0.02 & 0.98 & 5.59 & -1.27 & 4.32 & -0.03 & 0.99 \\
\hline \multirow{12}{*}{ 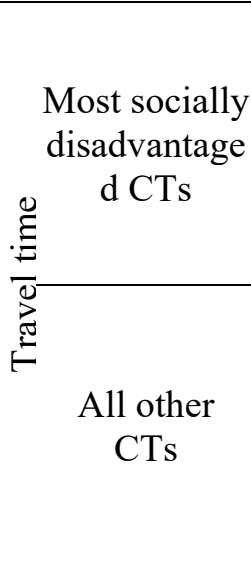 } & $5-6 \mathrm{AM}$ & 1.41 & -1.32 & 0.08 & -0.66 & 0.71 & 1.95 & -1.30 & 0.64 & -0.53 & 0.52 \\
\hline & $6-7 \mathrm{AM}$ & 3.20 & -1.98 & 1.22 & -0.42 & 0.86 & 1.58 & -1.35 & 0.22 & -0.56 & 0.35 \\
\hline & $7-8$ AM & 0.82 & -0.82 & 0.00 & -0.48 & 0.25 & 1.47 & -0.82 & 0.65 & -0.32 & 0.26 \\
\hline & $8-9$ AM & 0.44 & -0.61 & -0.17 & -0.38 & 0.20 & 0.97 & -0.75 & 0.22 & -0.30 & 0.21 \\
\hline & $9-12$ PM & 0.43 & -0.93 & -0.51 & -0.72 & 0.18 & 1.18 & -0.72 & 0.45 & -0.31 & 0.27 \\
\hline & $12-5 \mathrm{AM}$ & 1.83 & -0.79 & 1.04 & -0.18 & 0.42 & 1.82 & -0.75 & 1.07 & -0.25 & 0.31 \\
\hline & $5-6 \mathrm{AM}$ & 3.44 & -1.10 & 2.34 & 0.17 & 1.06 & 9.81 & -1.36 & 8.45 & 0.03 & 1.01 \\
\hline & $6-7 \mathrm{AM}$ & 4.56 & -1.60 & 2.96 & 0.08 & 1.03 & 14.71 & -1.42 & 13.28 & 0.05 & 1.03 \\
\hline & $7-8 \mathrm{AM}$ & 8.01 & -0.91 & 7.09 & 0.06 & 1.05 & 7.64 & -0.82 & 6.83 & -dce & 0.61 \\
\hline & $8-9$ AM & 8.27 & -0.75 & 7.52 & 0.03 & 1.04 & 10.25 & -0.69 & 9.56 & 0.00 & 0.73 \\
\hline & $9-12 \mathrm{PM}$ & 7.98 & -0.88 & 7.10 & 0.04 & 1.02 & 8.41 & -0.71 & 7.69 & 0.00 & 0.62 \\
\hline & $12-5 \mathrm{AM}$ & 13.47 & -0.82 & 12.64 & 0.02 & 1.04 & 10.96 & -0.71 & 10.26 & 0.01 & 0.83 \\
\hline
\end{tabular}

*Bold indicate indicates statistical significance in means t-test between consecutive time periods, e.g. 9-12 PM period and 12-5 AM period records. 


\section{TRENDS BY SOCIAL DECILE}

Figure 4-A compares, by decile, competitive accessibility over the day. It shows that there are disparities in the distribution of accessibility depending on the level of social deprivation a CT has. The figure also displays the transit benefits over time for the first decile (the most disadvantaged CTs) compared to the rest. Qualitative study of the figure shows that CTs in the fifth decile prevail. They experience better access by transit to low-wage and other-wage jobs throughout the day than any other areas. The first decile of CTs (the most socially disadvantaged decile) enjoy relatively high accessibility to jobs: they have the second highest level of accessibility to better-paid jobs and the third highest to low-wage jobs. Interestingly, the second and third deciles, which are still CTs with overall high levels social deprivation, experience a lower level of accessibility to both low-wage jobs and other-wage jobs. Furthermore, the seventh to ninth deciles, which are relatively wealthy CTs, experience the lowest level of accessibility by transit to job opportunities. Overall, peak competitive accessibility by public transit to job opportunities (low-wage jobs and other-wage jobs) for the five most socially disadvantaged deciles (excluding decile three) is between 5:00 am and 6:00 am. This indicates that generally more jobs are available for people occupying these deciles during the early morning. More specifically, more jobs are available for low wage service workers with early start times.

Figure 4-B displays the standardized average commute times for both job types by decile. Negative scores indicate shorter travel times, while positive scores indicate longer travel times. One major trend emerges, standardized transit travel time to jobs (both low-wage jobs and otherwage jobs) increases as the level of deprivation decreases, for all time periods. This indicates that socially disadvantaged people are located in CTs situated closer to their jobs by transit compared to those who are less deprived.

Figure 5 displays average commuting times for people travelling to low-wage jobs compared to other-wage jobs by decile. Commutes to low-wage jobs are shorter than commutes to other-wage jobs. These shorter commute times are significantly different $(p<0.001)$. Figure 5 also shows that this trend occurs in every decile. This tendency of lower commute times to lowwage jobs is relatively stable among the first six deciles, and increases for the other four deciles, so as deprivation decreases, commute times to low wage jobs increase.

Regarding the most socially disadvantaged CTs (decile one), the average travel time to low-wage jobs is 31.2 minutes, compared to 39.8 minutes for people living in all other CTs. This means that residents of socially disadvantaged CTs on average reduce their trips by nine minutes to reach low-wage jobs. This difference is statistically significant $(\mathrm{p}<0.05)$. Moreover, savings in transit travel time for people living in the most disadvantaged decile are even greater when travelling to other-paid jobs. In this case, their average transit travel time is 40.4 minutes, while it is 60.2 minutes for people living in all other CTs. The resulting 19.8 minute difference is significant $(\mathrm{p}<0.001)$. These findings suggest that residents of the most disadvantaged CTs are well served by transit since they experience the shortest travel time for both low-wage jobs and other-wage jobs compared to all other CTs. However, other sevices issues such as crowding may decrease service quality for these users. Yet, the increase in transit travel time, as CT groups become less deprived, indicates that less disadvantaged CTs are located further from their jobs by transit compared to the most disadvantaged CTs. 


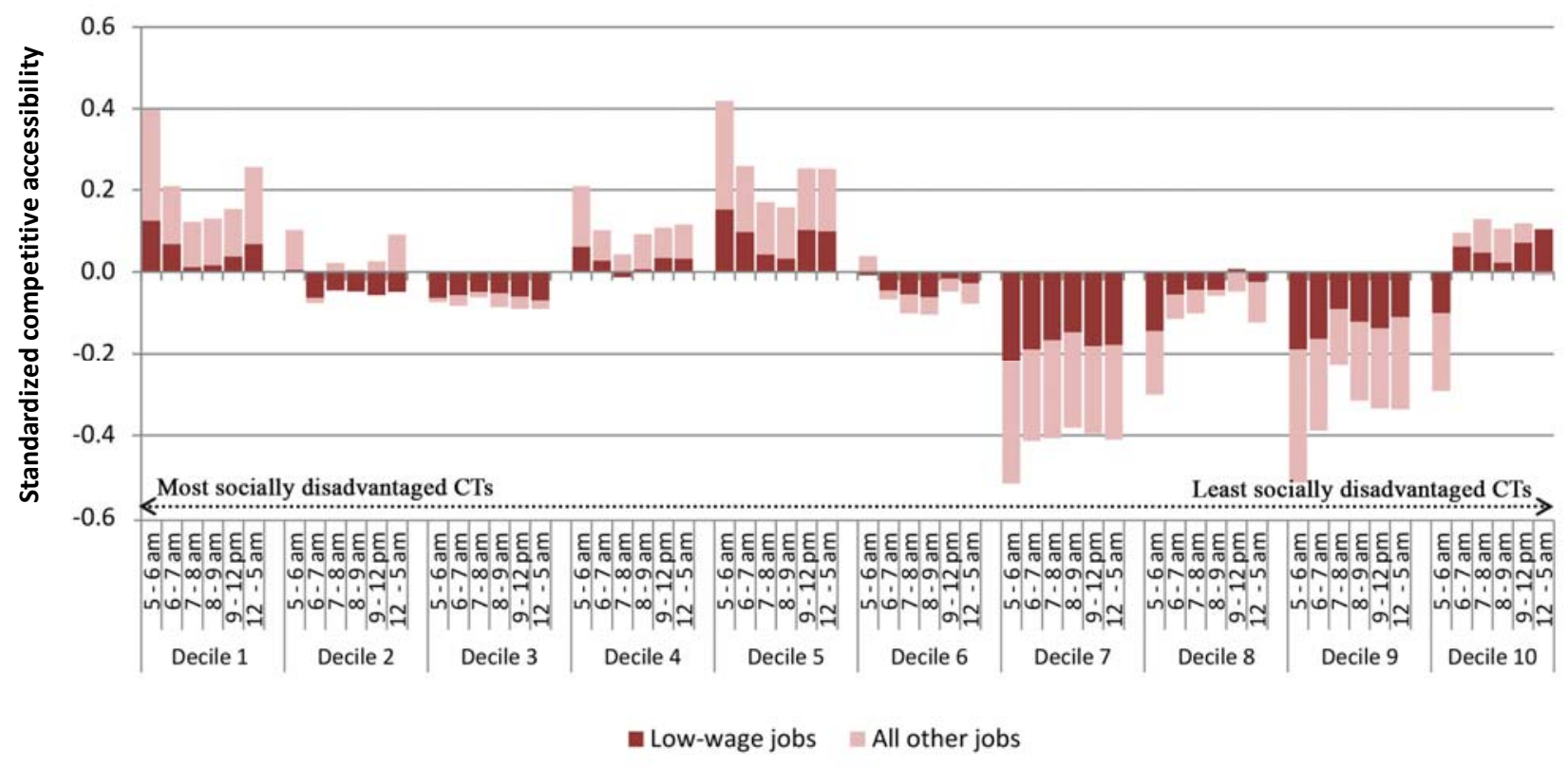

(4-A)

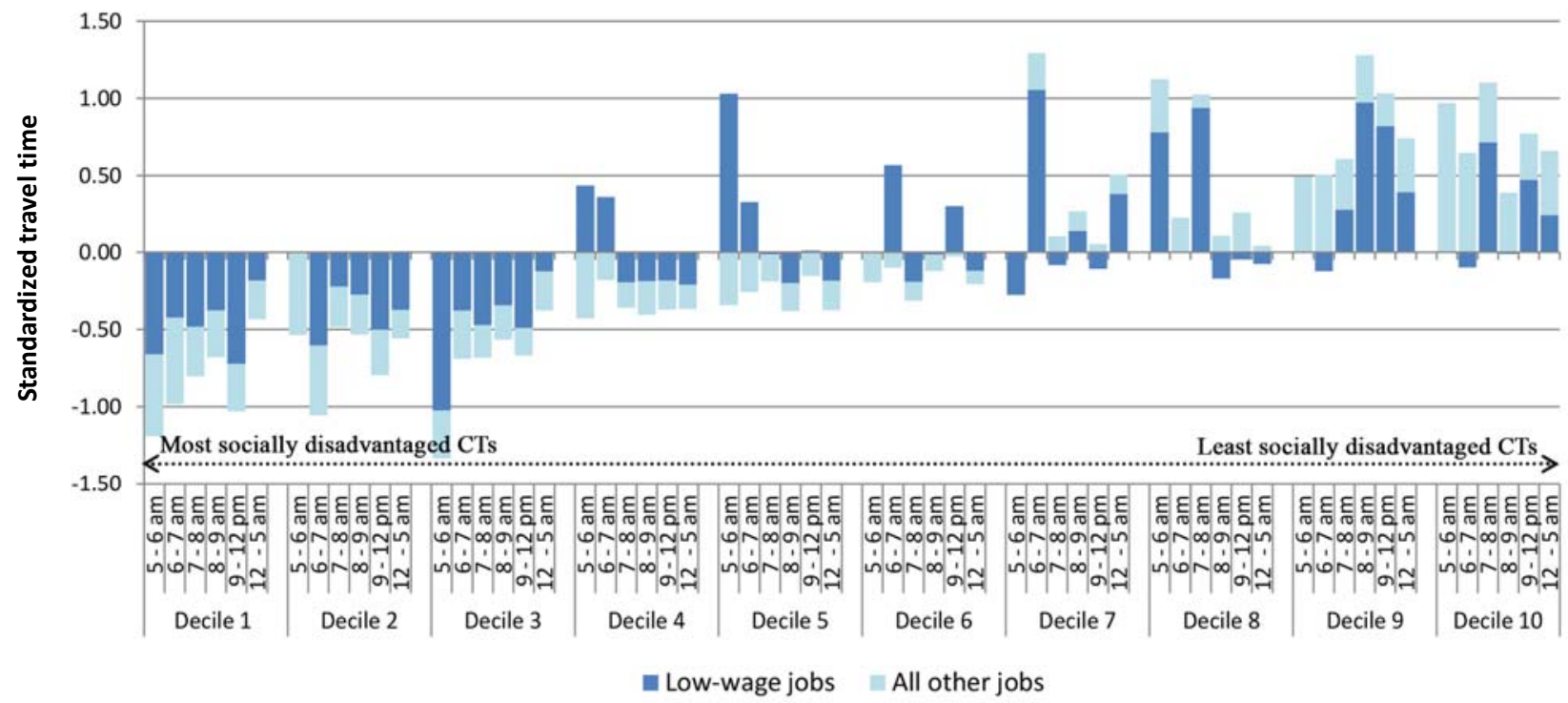

(4-B)

Figure 4: A-Standardized competitive accessibility to job type by CT decile on the social deprivation scale; and B-Standardized travel time to job type by CT decile on the scale of social deprivation 


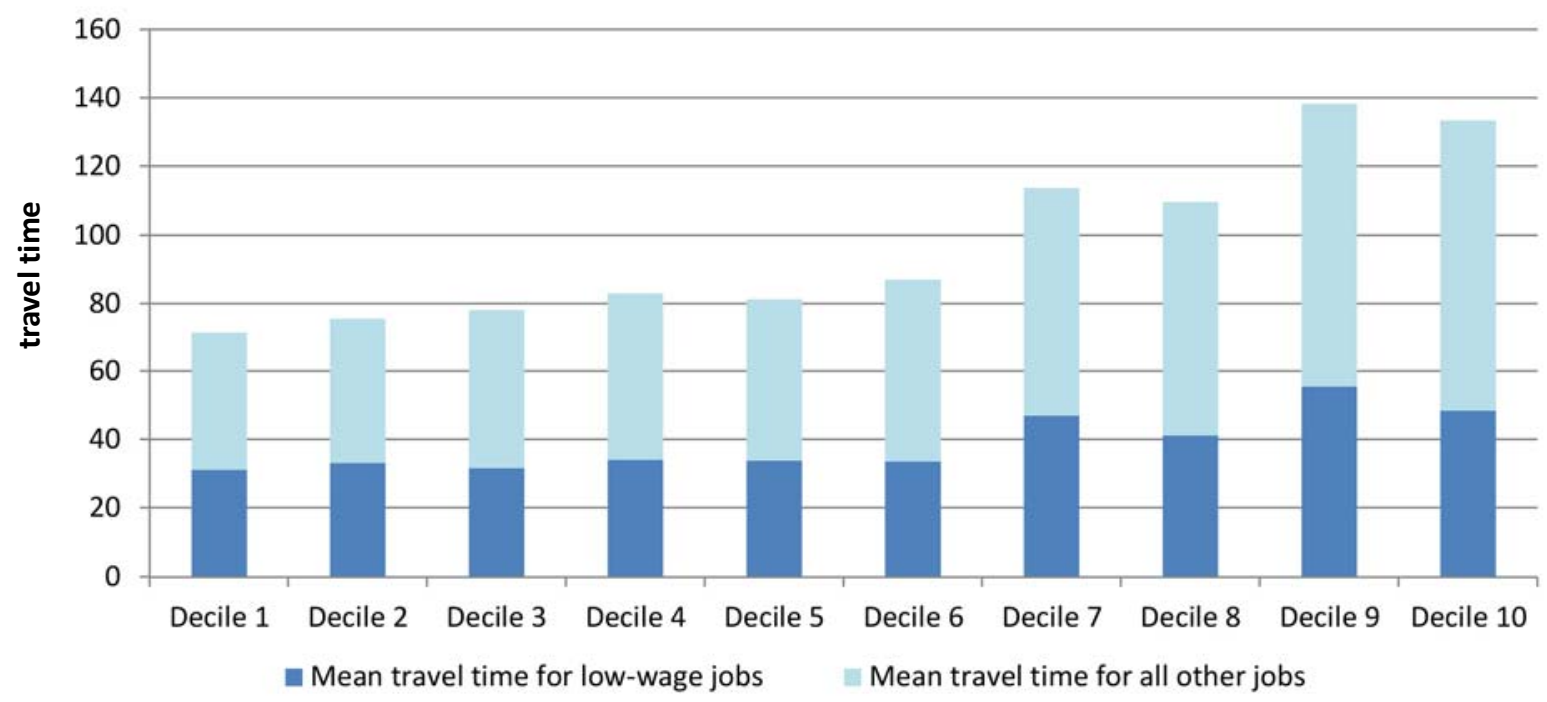

Figure 5: Average travel time to job categories by CT decile (not standardized)

Figure 6 illustrates the results of comparing the mean of standardized accessibility and the mean of standerized travel times by job type for the most socially-disadvantaged decile to all other deciles (the remaining 90\%) over the course of the day. The figure shows the standardized mean differences (i.e. the most socially-disadvantaged decile standardized mean minus all other deciles standardized mean) that have been genereated using a t-test.The results suggest that the most disadvantaged CTs possess better objectively measured accessibility to low-wage jobs by transit than all other CTs. Nevertheless, the differences are only significant between 5:00 am to 6:00 am $(\mathrm{p}<0.001)$. This signifies that when taking into account the number of jobs and people competing nearby, low-wage workers commuting from the most socially-disadvantaged CTs (decile 1) do not always have statistically significant better access to desired jobs throughout the day compared to residents coming from other CTs. However, the most disadvantaged CTs never experience lower access to low-wage jobs; either their access is better or equal to all other CTs.

Regarding jobs in other-wage categories, the most socially-disadvantaged CTs only have statistically significant better access compared to other CTs between 5:00 am and 6:00 am (p $<$ $0.001)$; between 6:00 am and 7:00 am $(\mathrm{p}<0.001)$; and from noon to 5:00 am $(\mathrm{p}<0.001)$ (Figure 6 ). Transportation agencies wishing to increase accessibility to employment opportunities for socially disadvantaged people should consider these results when planning transit services. Overall, the results suggest that equal or better accessibility to job opportunities to both low-wage and other-wage jobs demonstrates that vertical equity principles are sometimes applied in the region.

Regarding transit travel time to jobs, the most disadvantaged CTs experience consistently shorter transit commute times to low-wage jobs and to other-wage jobs. This finding is consistent with Figures 4 and 5. However, while the mean differences in commuting time are statistically significant at every time period for the other-wage jobs at the 0.05 level, they are only significant from 6:00 am to 7:00 am for the low-wage jobs. These results suggest that the most socially disadvantaged CTs have relatively better transit travel times to other-wage jobs than low-wage jobs compared to all other CTs, therefore people who are qualified to do these jobs, and who are living in the most disadvantaged CTs, experience the shortest travel times. 


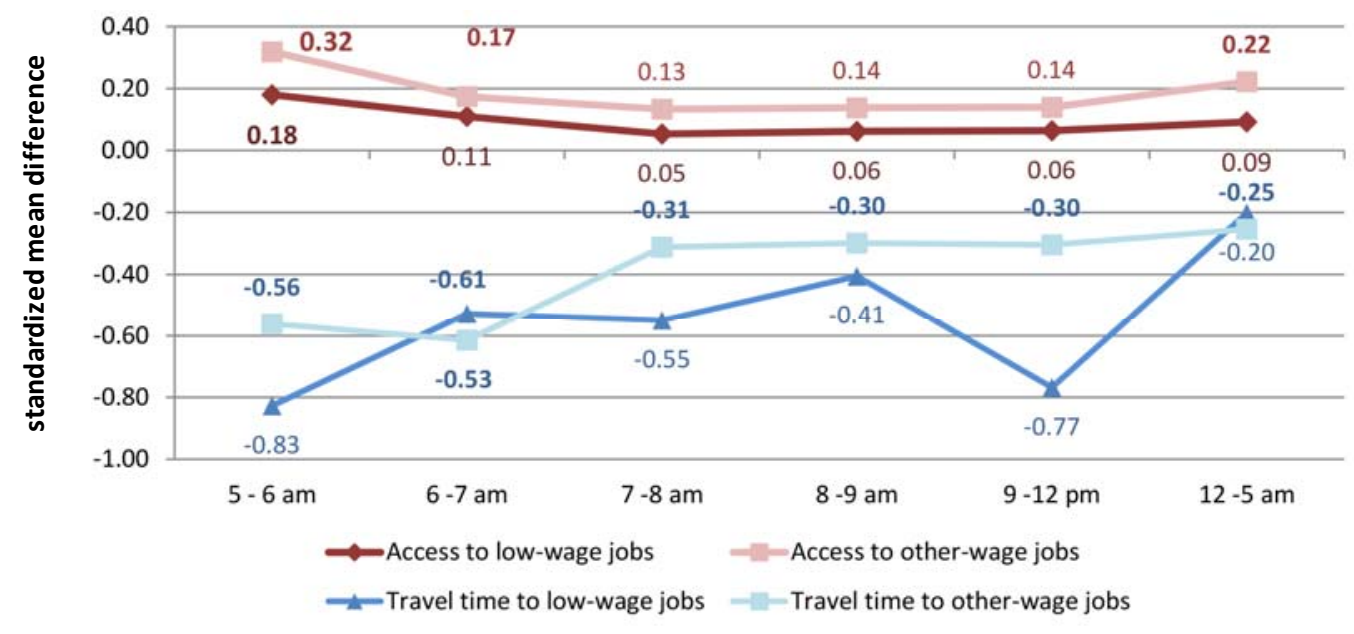

Bold numbers indicate statistically significant difference $(\mathrm{p}<0.05)$

Figure 6: Standardized mean difference in access between most disadvantaged CTs and other CTs by job type and travel time

Additional analysis reporting on spatial variation in accessibility and travel time among socially disadvantaged CTs (decile 1) for different parts of the GTHA is included in the supplementary material and summarized in Table S1. In addition, Table S2 of the supplementary material shows a comparison between the $10 \%$ most disadvantaged CTs' accessibility in different parts of the GTHA region to the $10 \%$ most disadvantaged CTs located within the City of Toronto (preamalgamation).

\section{DISCUSSION AND CONCLUSION}

In this paper, a competitive measure of accessibility is used to illustrate the current trend in accessibility to jobs for both the most socially disadvantaged CTs as well as all the other CTs. In fact, the results suggest that the most socially disadvantaged CTs in the GTHA experience equitable levels of transit benefits over a 24-hour period. Taking into account competition, access to low-wage jobs and all other jobs for the most socially disadvantaged decile is never significantly lower than the average access of all other CTs. Generally, better access to job opportunities for the most socially disadvantaged CTs is reflected in shorter travel times. More specifically, the most socially disadvantaged CTs experience better access early in the morning (between 5:00 am and 6:00 am) for low-wage jobs compared to other CTs. This may be due to more jobs being offered at this time for residents of these areas. These areas also have statistically significant shorter travel times to low wage jobs between 6:00 am and 7:00 am, highlighting the transit system's benefits. Results are similar for travel to other-wage jobs. Spatially, decile 1 CTs located within the boundaries of the pre-amalgamated City of Toronto, Hamilton and Peel regions benefit the most from the transit services; they have better accessibility. In contrast, attention should be paid to decile $1 \mathrm{CT}$ s located in the inner-suburbs of Toronto; these CTs benefit the least from current transit service.

Previous studies suggest that the location and quality of transit infrastructure, as well as the level of service provided, affect people's economic and social opportunities in a region. Fair distribution of transportation resources may result in improved accessibility for socially disadvantaged groups, whereas an inequitable distribution may harm the socially and 
economically disadvantaged (Krumholz \& Forester, 1990; Sanchez et al., 2003). This study examined spatial and temporal accessibility of transit services and jobs, by low and higher wage categories within the GTHA, Canada's largest urbanized region. A major finding of this study is that accessibility is generally better for the socially disadvantaged over the course of the day, who also experience shorter work travel times. Many of the findings correspond with the findings of Scott and Horner (2008) and Foth et al. (2013), which suggest that socially disadvantaged groups have statistically significant equal or better accessibility and lower transit travel times. However, the present study expands on these studies in three ways. First, it accounts for competition in estimating accessibility based on both jobs and workers, whereas the previous studies use a gravity-based measure of accessibility that does not account for competition to job opportunities. Second, accessibility to jobs by transit is estimated over the course of the entire day not just for a time-specific period. This allows for insight into the spatio-temporal variation of transit accessibility. Third, it uses data from the most recent NHS and increases the study area to include the entire GTHA. Foth et al. (2013) analyzed the evolution of transit accessibility to jobs only for the Toronto region from 1996 to 2006 . The present study, in contrast, assesses transit equity at a much greater scale as it combines two metropolitan areas and multiple transit agencies (eight in total). Findings suggest that although socially disadvantaged CTs have good levels of accessibility and shorter relative travel times, accessibility for different groups is not equal at all time periods, but often favors the most socially disadvantaged groups. However, it should be noted that time is only one measure of service quality, and therefore transit agencies must also evaluate the quality of service for different groups with regard to attributes such as crowding, cleanliness, and comfort.

The competitive measure of accessibility by transit that is used in this study is useful for understanding accessibility to both jobs and workers. Although it might be more difficult to explain compared to a regular gravity-based or cumulative opportunities measure, it reveals a new, more detailed, and less abstract picture regarding accessibility in the region. The southwest part of the GTHA, along the shore of Lake Ontario from Mississauga to Hamilton, has better competitive accessibility to both low-wage jobs and other-wage jobs than the center of the region (Toronto pre-amalgamation). This occurs because there is an imbalance between the location of workers and the locations of jobs. Simply put, more jobs are accessible from this area than workers. In addition, understanding how accessibility to jobs changes over the course of the day is essential for assessing equity and transit service/scheduling issues in the region as it can give a picture of how access changes over time. This analysis assesses equity in terms of transit by taking into account not only when people need to travel, but also when those jobs they are seeking are available. In other words, the method used in the paper provides an important time varying indicator of transit services enabling assessment of scheduling impacts on job accessibility, especially for socially disadvantaged groups, which to our knowledge has not previously been presented in the literature (Owen \& Levinson, 2014).

Findings from this study can also provide important insight into The Big Move, which is the regional transportation plan, prepared by Metrolinx - the agency of the Government of Ontario created to coordinate and improve transport integration across the region. This document outlines that "access to frequent, fast and affordable transit is crucial for equity and social cohesion (Metrolinx, 2008)." The plan also calls for the development of key performance indicators that aim to provide transit for individuals who need it the most by assessing the accessibility of transit as well as the transportation choices of low-income individuals (Metrolinx, 2008). Findings from this study address these goals and provide insight into the spatial and temporal accessibility in the region for the most socially disadvantaged decile over a 24 -hour 
period. Furthermore, for transit agencies to meet their accessibility and equity goals, they should not only focus on improving accessibility and travel time for the lowest decile, but also look at other groups in the region that do not currently have the same transit benefits as the lowest decile. Whereas in this study the accessibility for lowest social decile was compared to all other deciles, future research should consider how changes in accessibility over time could influence different deciles with the goal of increasing overall equity. Another important factor for future research is to consider the travel habits and transit accessibility between socially disadvantaged CTs and CTs that are not considered socially disadvantaged. Results may show differences in movement between different CTs, providing insight into where transit systems enable the socially disadvantaged to travel to, as well as the places they cannot reach. Overall, findings of this research are relevant for transit agencies operating in diverse regions as they provide insight as to how a competitive measure of accessibility can be developed and applied to evaluate and better understand transit systems. 


\section{REFERENCES}

Ades, J., Apparicio, P., \& Séguin, A. (2012). Are new patterns of low - income distribution emerging in Canadian metropolitan areas? The Canadian Geographer/Le Géographe canadien, 56(3), 339-361.

Anderson, P., Owen, A., \& Levinson, D. (2012). The Time Between: Continuously-defined accessibility functions for schedule-based transportation systems. Paper presented at the 1st European Symposium on Quantitative Methods in Transportation Systems.

Atkinson, A. B. (1983). The economics of inequality: Clarendon Press Oxford.

Bunting, T., Walks, A. R., \& Filion, P. (2004). The uneven geography of housing affordability stress in Canadian metropolitan areas. Housing Studies, 19(3), 361-393.

Delafontaine, M., Neutens, T., Schwanen, T., \& Van de Weghe, N. (2011). The impact of opening hours on the equity of individual space-time accessibility. Computers, environment and urban systems, 35(4), 276-288.

Delbosc, A., \& Currie, G. (2011). Using Lorenz curves to assess public transport equity. Journal of Transport Geography, 19(6), 1252-1259.

Duclos, J., \& Araar, A. (2007). Poverty and equity: Measurement, policy and estimation with $D A D$ (Vol. 2): Springer.

El-Geneidy, A., \& Levinson, D. (2006). Access to destinations: Development of accessibility measures: Minnesota Department of Transportation, Research Services Section.

Field, B. C., \& Olewiler, N. D. (2011). Environmental Economics: Third Canadian Edition: Toronto: MacGraw-Hill Ryerson.

Foth, N., Manaugh, K., \& El-Geneidy, A. (2013). Towards equitable transit: Examining transit accessibility and social need in Toronto, Canada, 1996-2006. Journal of Transport Geography, 29, 1-10.

Geurs, K., \& van Eck, R. (2001). Accessibility measures: Review and applications. Evaluation of accessibility impacts of land-use transportation scenarios, and related social and economic impact.

Geurs, K., \& Van Wee, B. (2004). Accessibility evaluation of land-use and transport strategies: review and research directions. Journal of Transport Geography, 12(2), 127-140.

Government of Canada. (2014). Toronto Wage Report. Job Bank. 2014, from http://www.jobbank.gc.ca/LMI_report_area.do?\&area=9219\&reportOption=wage

Grengs, J. (2010). Job accessibility and the modal mismatch in Detroit. Journal of Transport Geography, 18(1), 42-54.

Handy, S., \& Niemeier, D. (1997). Measuring accessibility: an exploration of issues and alternatives. Environment and Planning A, 29, 1175-1194.

Hansen, W. G. (1959). How accessibility shapes land use. Journal of the American Institute of Planners, 25(2), 73-76.

Houston, D. (2005). Methods to test the spatial mismatch hypothesis. Economic Geography, 81(4), 407-434.

Jones, P., \& Lucas, K. (2012). The social consequences of transport decision-making: Clarifying concepts, synthesising knowledge and assessing implications. Journal of Transport Geography, 21, 4-16.

Kain, J. (1968). Housing segregation, negro employment, and metropolitan decentralization. The Quarterly Journal of Economics, 175-197. 
Kain, J. (1992). The spatial mismatch hypothesis: Three decades later. Housing policy debate, 3(2), 371-460.

Kaplan, S., Popoks, D., Prato, C. G., \& Ceder, A. A. (2014). Using connectivity for measuring equity in transit provision. Journal of Transport Geography, 37, 82-92.

Kawabata, M., \& Shen, Q. (2006). Job accessibility as an indicator of auto-oriented urban structure: a comparison of Boston and Los Angeles with Tokyo. Environment and Planning B: Planning and Design, 33, 115-130.

Kim, H., \& Kwan, M. (2003). Space-time accessibility measures: A geocomputational algorithm with a focus on the feasible opportunity set and possible activity duration. Journal of Geographical Systems, 5(1), 71-91.

Krumholz, N., \& Forester, J. (1990). Making Equity Planning Work: Leadership in the Public ssctor. Philadelphia: Temple University Press.

Levinson, D. M. (1998). Accessibility and the journey to work. Journal of Transport Geography, 6(1), 11-21.

Litman, T. (2002). Evaluatin transportation equity. World Transport Policy \& Practice, 8(2), 5065.

Louka, E. (2006). International environmental law: Fairness, effectiveness, and world order: Cambridge University Press.

Mackenzie, H., \& Stanford, J. (2008). A living wage for Toronto: Canadian Centre for Policy Alternatives.

Martens, K. (2012). Justice in transport as justice in accessibility: Applying Walzer's 'Spheres of Justice'to the transport sector. Transportation, 39(6), 1035-1053.

Metrolinx. (2008). The Big Move: Transforming Transportation in the Greater Toronto and Hamilton Area. from http://www.metrolinx.com/thebigmove

Morris, J. M., Dumble, P. L., \& Wigan, M. R. (1979). Accessibility indicators for transport planning. Transportation Research Part A: General, 13(2), 91-109.

Murray, A. T., \& Davis, R. (2001). Equity in regional service provision. Journal of Regional Science, 41(4), 557-600.

OpenTripPlanner. (2014). Retrieved July 30, 2014, from http://www.opentripplanner.org/

Owen, A., \& Levinson, D. (2013). Modeling the commute mode share of transit using continuous accessibility to jobs. Paper presented at the Transportation Research Board 93rd Annual Meeting, Washington, DC.

Owen, A., \& Levinson, D. (2014). Access across America: Transit 2014 (Vol. .). Minneapolis, Minnesota: University of Minnesota Center for Transportation Studies.

Ramjerdi, F. (2006). Equity measures and their performance in transportation. Transportation Research Record: Journal of the Transportation Research Board, 1983(1), 67-74.

Rawl, J. (1971). A theory of justice. Bamforth N, Malik M and O'Cinneide C.

Sanchez, T., Stolz, R., \& Ma, J. (2003). Moving to equity: Addressing inequitable effects of transportation policies on minorities Civil Rights Project at Hardvard University. Cambridge, MA: Harvard University.

Santos, B., Antunes, A., \& Miller, E. J. (2008). Integrating equity objectives in a road network design model. Transportation Research Record: Journal of the Transportation Research Board, 2089(1), 35-42.

Scott, D., \& Horner, M. (2008). Examining the role of urban form in shaping people's accessibility to opportunities: An exploratory spatial data analysis. Journal of Transport and Land Use, 1(2). 
Shearmur, R., Coffey, W., Dube, C., \& Barbonne, R. (2007). Intrametropolitan employment structure: Polycentricity, scatteration, dispersal and chaos in Toronto, Montreal and Vancouver, 1996-2001. Urban Studies, 44(9), 1713-1738.

Shearmur, R., \& Coffey, W. J. (2002). A tale of four cities: intrametropolitan employment distribution in Toronto, Montreal, Vancouver, and Ottawa-Hull, 1981-1996. Environment and Planning A, 34(4), 575-598.

Shen, Q. (1998). Location characteristics of inner-city neighborhoods and employment accessibility of low-wage workers. Environment and Planning B: Planning and Design, 25(3), 345-365.

Soanes, C., \& Stevenson, A. (Eds.). (2003). Oxford: Oxford University Press.

Talen, E. (1998). Visualizing fairness: Equity maps for planners. Journal of the American Planning Association, 64(1), 22-38.

Townsend, P., Phillimore, P., \& Beattie, A. (1988). Health and deprivation: Inequality and the North: Croom Helm London.

van Wee, B., \& Geurs, K. T. (2011). Discussing equity and social exclusion in accessibility evaluations. European Journal of Transport and Infrastructure Research, 11(4).

Williams, A., \& Cookson, R. (2000). Equity in health. Handbook of Health Economics, 1, 18631910. 